Article

\title{
Association of Serum High-Density Lipoprotein Cholesterol with High Blood Pressures at Checkup: Results of Kanagawa Investigation of Total Checkup Data from the National Database-9 (KITCHEN-9)
}

\author{
Kei Nakajima ${ }^{1,2, *(\mathbb{D})}$, Manami Igata ${ }^{1}$, Ryoko Higuchi ${ }^{1}$, Kotone Tanaka $^{1}$, Kaori Mizusawa ${ }^{1}$ and Teiji Nakamura $^{1}$ \\ 1 School of Nutrition and Dietetics, Faculty of Health and Social Services, Kanagawa University of \\ Human Services, 1-10-1 Heisei-cho, Yokosuka 238-8522, Japan; 62020002.pn0@kuhs.ac.jp (M.I.); \\ higuchi-nk3@kuhs.ac.jp (R.H.); tanaka-rt8@kuhs.ac.jp (K.T.); mizusawa.hsp@kuhs.ac.jp (K.M.); \\ nakamura-t@kuhs.ac.jp (T.N.) \\ 2 Saitama Medical Center, Department of Endocrinology and Diabetes, Saitama Medical University, \\ 1981 Kamoda, Kawagoe 350-8550, Japan \\ * Correspondence: nakajima-rsh@kuhs.ac.jp; Tel.: +81-046-828-2660; Fax: +81-046-828-2661
}

check for updates

Citation: Nakajima, K.; Igata, M.; Higuchi, R.; Tanaka, K.; Mizusawa, K.; Nakamura, T. Association of Serum High-Density Lipoprotein Cholesterol with High Blood Pressures at Checkup: Results of Kanagawa Investigation of Total Checkup Data from the National Database-9 (KITCHEN-9). J. Clin. Med. 2021, 10, 5118. https://doi.org/ $10.3390 / \mathrm{jcm} 10215118$

Academic Editors: Francesca Mallamaci and Giovanni Tarantino

Received: 20 September 2021 Accepted: 28 October 2021 Published: 30 October 2021

Publisher's Note: MDPI stays neutral with regard to jurisdictional claims in published maps and institutional affiliations.

Copyright: (c) 2021 by the authors. Licensee MDPI, Basel, Switzerland. This article is an open access article distributed under the terms and conditions of the Creative Commons Attribution (CC BY) license (https:// creativecommons.org/licenses/by/ $4.0 /)$.

\begin{abstract}
Background: although high-density lipoprotein has cardioprotective effects, the association between serum high-density lipoprotein cholesterol (HDL-C) and hypertension is poorly understood. Therefore, we investigated whether high and low concentrations of HDL-C are associated with high blood pressure (HBP) using a large healthcare dataset. Methods: in a community-based crosssectional study of 1,493,152 Japanese people (830,669 men and 662,483 women) aged 40-74 years who underwent a health checkup, blood pressures automatically measured at healthcare center were investigated in nine HDL-C groups (20-110 mg/dL or over). Results: crude U-shaped relationship were observed between the nine HDL-C and blood pressures in both men and women. Logistic regression analysis showed left-to-right inverted J-shaped relationships between HDL-C and odds ratios for $\mathrm{HBP}$ ( $\geq 140 / 90 \mathrm{mmHg}$ and/or pharmacotherapy), with lower limits of 90-99 $\mathrm{mg} / \mathrm{dL}$ in both sexes, which were unchanged after adjusting for confounding factors. However, further adjustment for body mass index and serum triglyceride concentration revealed positive linear associations between HDL-C and HBP, although blunt U-shaped associations remained in nonalcohol drinkers. Conclusion: both low and extremely high HDL-C concentrations are associated with HBP. The former association might be dependent on excess fat mass concomitant with low HDL-C, whereas the latter association may be largely dependent on frequent alcohol consumption.
\end{abstract}

Keywords: high-density lipoprotein cholesterol; hypertension; blood pressure; low high-density lipoprotein cholesterol; extremely high high-density lipoprotein cholesterol; body mass index; big data

\section{Introduction}

High-density lipoprotein (HDL) is considered to have cardioprotective effects, which were confirmed repeatedly in molecular, cellular, animal, and human studies [1-5]. Therefore, individuals with a high serum HDL cholesterol (HDL-C) concentration are considered to be at a lower risk of cardiovascular disease (CVD) and mortality according to the concepts of "the higher, the better" and "longevity syndrome" [2,6,7]. However, in the past decade, several studies showed a U-shaped relationship between HDL-C and CVD, non-CVD, and all-cause mortality [8-14], which suggests that, like low HDL-C, very or extremely high HDL-C is not beneficial for overall health. Moreover, increasing HDL-C with pharmacotherapy, including cholesteryl ester transfer protein (CETP) inhibitors, did not show protective effects against CVD and mortality [15-18]. Among the plausible causes of adverse reactions with CETP inhibitors (torcetrapib and evacetrapib), a slight increase 
in blood pressure $[19,20]$ and vasoactive effects [21] were observed and possibly were considered as markers of profound adverse reactions due to neuroendocrine or vasomotor effects [15].

Hypertension is a leading cause of CVD and mortality worldwide. However, to date, the fundamental relationship between serum HDL-C concentration and blood pressure was poorly argued, probably because an inverse relationship was observed between serum HDL-C and CVD and its risk factors [4,5].

Unexpectedly, however, instead of an inverse relationship, a slight U-shaped relationship, a left-to-right inverted J-shaped relationship $[9,11,13]$, or a positive linear relationship $[12,14]$ between circulating HDL-C and blood pressure or hypertension were observed in several studies. Despite these relationships being noted, authors did not particularly address them; hence, their statistical significance is unclear.

To date, three studies addressed the association between HDL-C concentration and hypertension [22-24]. Additionally, we recently showed an association between extremely high HDL-C $(\geq 110 \mathrm{mg} / \mathrm{dL})$ and hypertensive retinopathy in a general population who underwent fundus examinations [25]. Our results suggested a positive association between HDL-C concentration and blood pressure/hypertension-related pathology. However, these four studies [22-25], which examined the pathophysiology of very low and high HDL-C concentrations (e.g., $<30 \mathrm{mg} / \mathrm{dL}$ and $\geq 90 \mathrm{mg} / \mathrm{dL}$ ), consisted of relatively small sample sizes $(<5000$ participants in total). Actually, the number of subjects with hypertensive retinopathy was only 16 in the extremely high HDL-C group in our previous study [25]. Consequently, it was difficult to conduct an appropriate statistical analysis with proper adjustment for relevant confounding factors (covariates) in the low and very high HDL$C$ groups, which hampered disclosure of a latent overall association between HDL-C concentration and hypertension.

In this context, we investigated the crude and latent (adjusted for multiple background factors) associations between serum HDL-C concentration and high blood pressure (HBP) measured at checkup in a community-based cross-sectional study using a big healthcare dataset of 1.5 million general Japanese people [26]. Although hypertension is to be determined after consideration of home blood pressures $[27,28]$, it is unfeasible to instruct the measurement of home blood pressure to huge population without suspicion for hypertension. Therefore, in this study, we investigated HBP at checkup, instead of hypertension.

\section{Methods}

\subsection{Study Design and Subjects}

We performed a composite multidisciplinary study involving secondary use of annual health checkup data in Japan (Kanagawa Investigation of the Total Checkup Data from the National Database [KITCHEN]) to investigate clinical factors primarily associated with cardiometabolic disease. Details of the study concept and design were published elsewhere [26]. Since 2008, all Japanese people aged 40-74 years are supposed to undergo a yearly itemized health checkup managed by the Ministry of Health, Labour, and Welfare (MHLW) $[26,29]$. The present study included all individuals who underwent these specific health checkups and who were living in Kanagawa Prefecture.

After religious review of our research project by the MHLW of Japan, our protocol was accepted in December 2016. We received digitally recorded anonymous data from the MHLW of Japan in September 2017, as part of its nationwide program involving the provision of medical data to third parties [30]. To conceal the identity of specific individuals, their ages were categorized as $40-44,45-49,50-54,55-59,60-64,65-69$, or 70-74 years. In this study, however, to evaluate subject age as a single numeric value, we transformed the age groups into substituted ages corresponding to the median of each age group $(42,47,52$, $57,62,67$, and 72 years).

We initially reviewed data collected from 1,819,173 people aged 40-74 years who attended health checkups between April 2014 and March 2015. After excluding subjects with at least one missing continuous or categorical data point, 1,493,152 subjects were 
included in the study analysis (830,669 males and 662,483 females). Some proportions of subjects were treated with pharmacotherapy for hypertension, diabetes, and dyslipidemia. However, it is unclear whether individuals with treatment by a CEPT inhibitor were included in this study.

\subsection{Measurements}

Anthropometric and laboratory measurements were obtained on the morning following an overnight fast. Body weight and height were objectively measured by trained institutional staff members. Body mass index (BMI) was calculated as mass (in kg) divided by the square of height $\left(\mathrm{m}^{2}\right)$. Biochemical measurements were performed automatically using standard methods. Serum low-density lipoprotein cholesterol (LDL-C), HDL-C, and triglyceride (TG) concentrations were measured automatically following rigorous instructions from the MHLW [26].

In a quiet room conditioned preferably at $20-25^{\circ} \mathrm{C}$, after five minutes of resting in the sitting position, blood pressure at the upper arm was determined using an automated upper arm cuff type (typically, $13 \mathrm{~cm}$ in width and 22-24 cm in length) sphygmomanometer at the healthcare institute performing the checkups [26,31,32]. Blood pressure was measured once in $70 \%$ of patients and twice in $30 \%$ of patients, who had suspicions about the first result of blood pressure due to the inadequate resting or measurements. The first result was used in $20 \%$ of subjects who confirmed that fist measurement was properly conducted after additional measurement. Otherwise, the second result was used in $10 \%$ of subjects.

HBP was defined as having either of systolic blood pressure of $\geq 140 \mathrm{mmHg}$, diastolic blood pressure of $\geq 90 \mathrm{mmHg}$, or pharmacotherapy for hypertension. Pulse pressure was calculated as systolic minus diastolic blood pressure. Subjects were classified into nine categories at 10-mg/dL HDL-C concentration intervals: 20-39, 40-49, 50-59, 60-69, 70-79, 80-89, 90-99, 100-109, and $\geq 110 \mathrm{mg} / \mathrm{dL}$.

Because serum HDL-C concentration and blood pressure are elevated in people who frequently consume alcohol [33,34], to eliminate the effect of alcohol consumption on serum HDL-C and blood pressure, we investigated the association between these variables in a subgroup of subjects who answered "hardly drink (including cannot drink)" when asked "How often do you drink alcohol (sake, distilled spirits, beer, liquor and so)?" [26]. Other answers were "everyday" and "occasional".

We also investigated the association between HDL-C concentrations and pharmacotherapy for hypertension, which was diagnosed considering home blood pressure independently of current blood pressure measured at the checkup. These results are provided in the Supplementary Materials, Figure S1.

\subsection{Statistical Analysis}

Data are expressed as mean \pm standard deviation or median (interquartile range). Differences in continuous and categorical variables were evaluated by analysis of variance (ANOVA) and the $\chi^{2}$ test, respectively. Trends in the prevalence of dichotomized categorical variables across the increasing HDL-C strata were evaluated by Cochran-Armitage tests. A logistic regression model was used to evaluate the associations between the nine HDL$\mathrm{C}$ concentration categories and HBP with adjustment for potential confounding factors (age, sex, BMI, TG, LDL-C, glycated hemoglobin (HbA1c) (National Glycohemoglobin Standardization Program value), pharmacotherapy for diabetes mellitus, dyslipidemia, smoking, frequency of alcohol consumption, and habitual exercise), and yielded adjusted odds ratios (ORs) and 95\% confidence intervals (CIs). Of note, because in general, HDL-C is inversely associated with BMI and serum TG concentration, the adjustment for BMI and TG was separately conducted. All statistical analyses were performed using SAS-Enterprise Guide (SAS-EG 7.1) in SAS software, version 9.4 (SAS Institute, Cary, NC, USA). $p$ values of $<0.05$ were considered statistically significant. 


\section{Results}

Table 1 shows the characteristics of subjects according to the nine HDL-C concentration categories. There were 50,064 subjects with an HDL-C concentration of $\geq 100 \mathrm{mg} / \mathrm{dL}$ (3.4\% of the total), and nearly $75 \%$ of these were female. Overall, all continuous variables (blood pressure, pulse pressure, BMI, TG, LDL-C, and HbA1c), except age, were lower in the higher HDL-C groups compared with that of the lower HDL-C groups (ANOVA, all $p<0.0001$ ). The prevalence of pharmacotherapy (for hypertension, diabetes mellitus, and dyslipidemia), CVD history, and current smoking were also lower (Cochran-Armitage test, all $p<0.0001)$. However, the prevalence of the female sex, daily alcohol consumption, and habitual exercise was higher in the higher HDL-C groups compared with that of the lower HDL-C groups (all $p<0.0001$ ).

$\mathrm{U}$ or left-to-right inverted J-shaped relationships were observed between blood pressures and the nine HDL-C concentration categories in both men and women (Figure 1). Similar trends were also observed in the relationships between pulse pressures and the nine HDL-C concentrations.

HBP was observed in $31.7 \%$ of the whole, $36.4 \%$ of men, and $25.8 \%$ of women, respectively. Table 2 shows the prevalence of HBP in the nine HDL-C concentrations. Left-to-right inverted J-shaped relationships with a bottom of HDL-C of 90-99 mg/dL were observed between HBP and HDL-C categories in the whole (23.7\%) and women (19.7\%), whereas U-shaped relationship with a bottom of HDL-C of 70-79 mg/dL (33.8\%) were observed in men. Of note, high prevalence of HBP was observed in both ends of HDL-C category in men $(40.9 \%$ for the lowest and $40.8 \%$ for the highest).

In the results of logistic regression analysis, similar trends were observed between the nine HDL-C categories and their crude and confounders-adjusted ORs for HBP (Figure 2). Left-to-right inverted J-shaped relationship with a bottom of HDL-C of 90-99 mg/dL remained in men after adjustment for confounders except for BMI and serum TG. However, after further adjustment for BMI and serum TG, the associations between low and normal HDL-C categories $(\leq 90 \mathrm{mg} / \mathrm{dL}$ ) and HBP were inverted (the ORs were reduced to less than 1.0) and the overall relationships between HDL-C concentration and HBP transformed into positive linear relationships in both men and women, which remained after adjustment for LDL-C and $\mathrm{HbA1c}$.

Although data are not expressed, the daily and occasional alcohol consumptions were significantly associated with HBP compared with that of no alcohol consumption in the whole subjects (OR (95\%IRs), 1.72 (1.71-1.74) and 1.59 (1.57-1.61)), even after adjustment for age, sex, smoking, habitual exercise, and pharmacotherapy for diabetes and dyslipidemia.

When the outcome of HBP was replaced with the presence of pharmacotherapy for hypertension in the same models above (Figure S1), left-to-right inverted J-shaped relationship with a bottom of HDL-C of 100-109 mg/dL were observed in the whole. However, after adjustment for confounders including BMI and TG, instead of positive linear, blunt U-shaped relationship with a bottom of HDL-C of 70-79 mg/dL for men and $80-89 \mathrm{mg} / \mathrm{dL}$ for women were observed. 
Table 1. Clinical characteristics of subject.

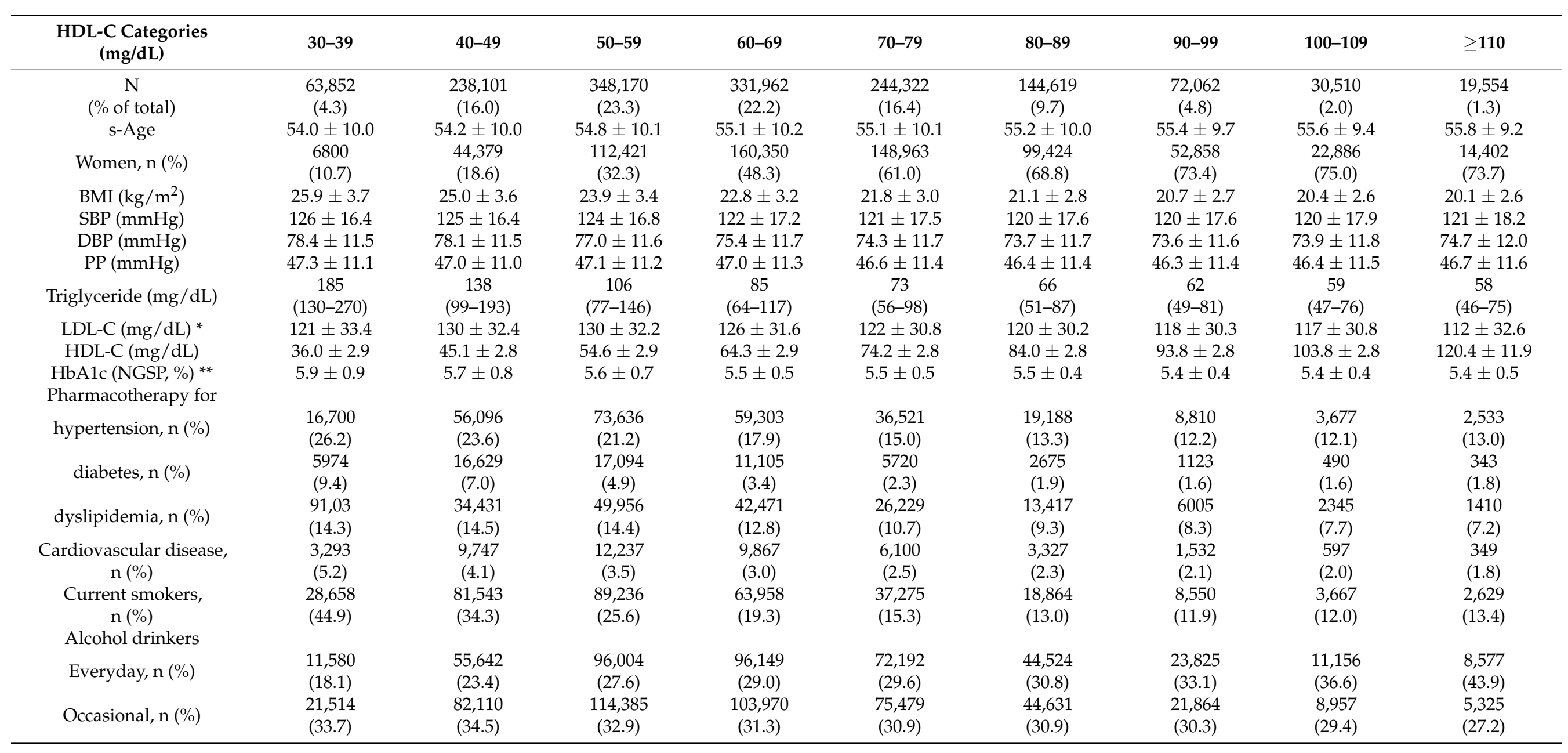


Table 1. Cont.

\begin{tabular}{|c|c|c|c|c|c|c|c|c|c|}
\hline $\begin{array}{l}\text { HDL-C Categories } \\
(\mathrm{mg} / \mathrm{dL})\end{array}$ & $30-39$ & $40-49$ & $50-59$ & $60-69$ & $70-79$ & $80-89$ & 90-99 & 100-109 & $\geq 110$ \\
\hline Non, n (\%) & $\begin{array}{c}30,758 \\
(48.2)\end{array}$ & $\begin{array}{c}100,349 \\
(42.2)\end{array}$ & $\begin{array}{c}13,7781 \\
(39.6)\end{array}$ & $\begin{array}{c}131,843 \\
(39.7)\end{array}$ & $\begin{array}{l}96,651 \\
(39.6)\end{array}$ & $\begin{array}{l}55,464 \\
(38.4)\end{array}$ & $\begin{array}{l}26,373 \\
(36.6)\end{array}$ & $\begin{array}{l}10,397 \\
(34.1)\end{array}$ & $\begin{array}{l}5,652 \\
(28.9)\end{array}$ \\
\hline $\begin{array}{c}\text { Regular exercisers, } \\
\mathrm{n}(\%)\end{array}$ & $\begin{array}{l}14,582 \\
(22.8)\end{array}$ & $\begin{array}{l}60,875 \\
(25.6)\end{array}$ & $\begin{array}{l}99,252 \\
(28.5)\end{array}$ & $\begin{array}{c}102,162 \\
(30.8)\end{array}$ & $\begin{array}{l}78,890 \\
(32.3)\end{array}$ & $\begin{array}{l}48,424 \\
(33.5)\end{array}$ & $\begin{array}{l}25,094 \\
(34.8)\end{array}$ & $\begin{array}{l}10,874 \\
(35.6)\end{array}$ & $\begin{array}{l}7,300 \\
(37.3)\end{array}$ \\
\hline
\end{tabular}

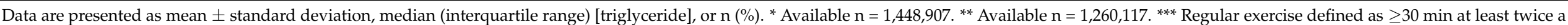

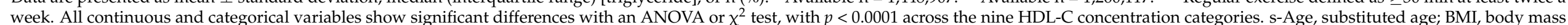
index; HDL-C, high-density lipoprotein cholesterol; SBP, systolic blood pressure; DBP, diastolic blood pressure; PP, pulse pressure. 
A

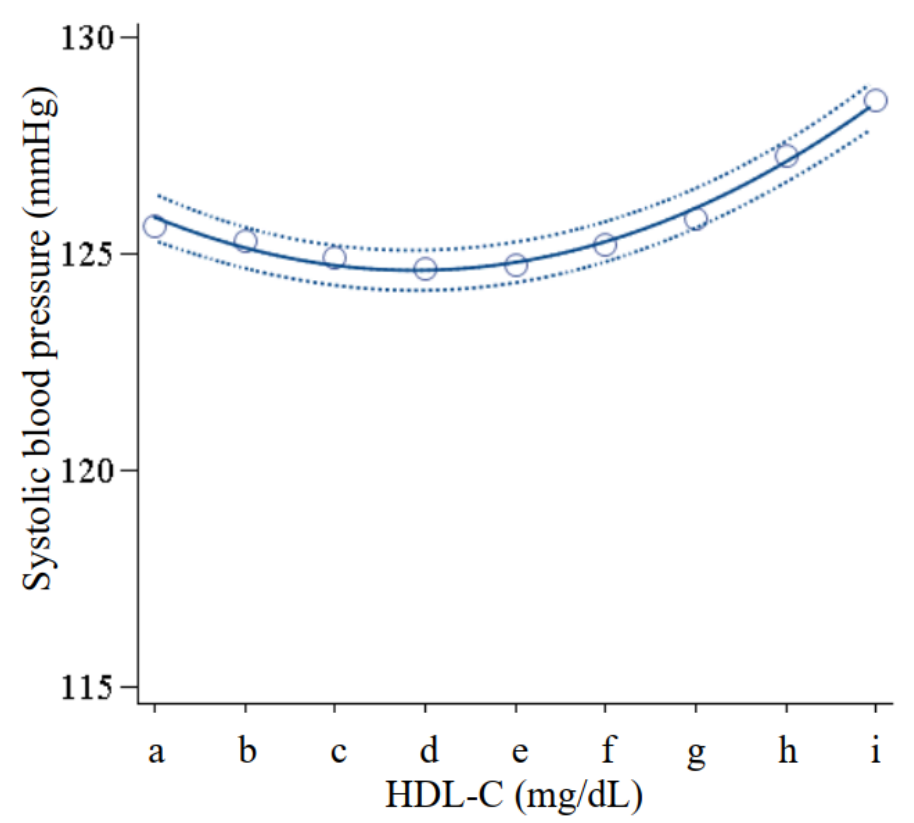

C

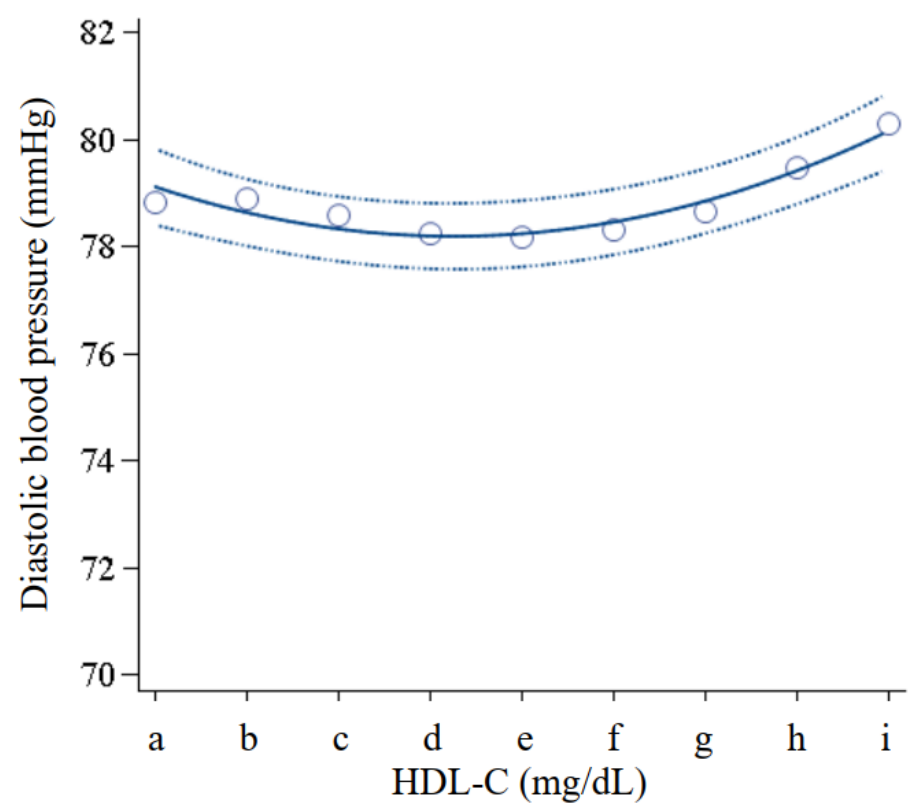

B

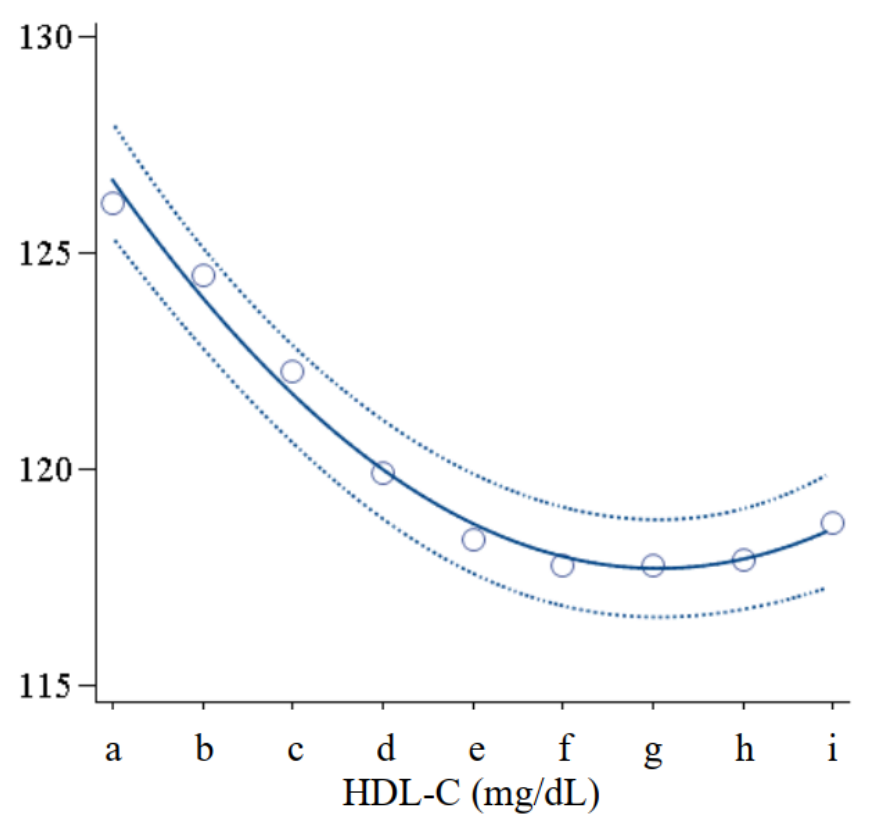

D

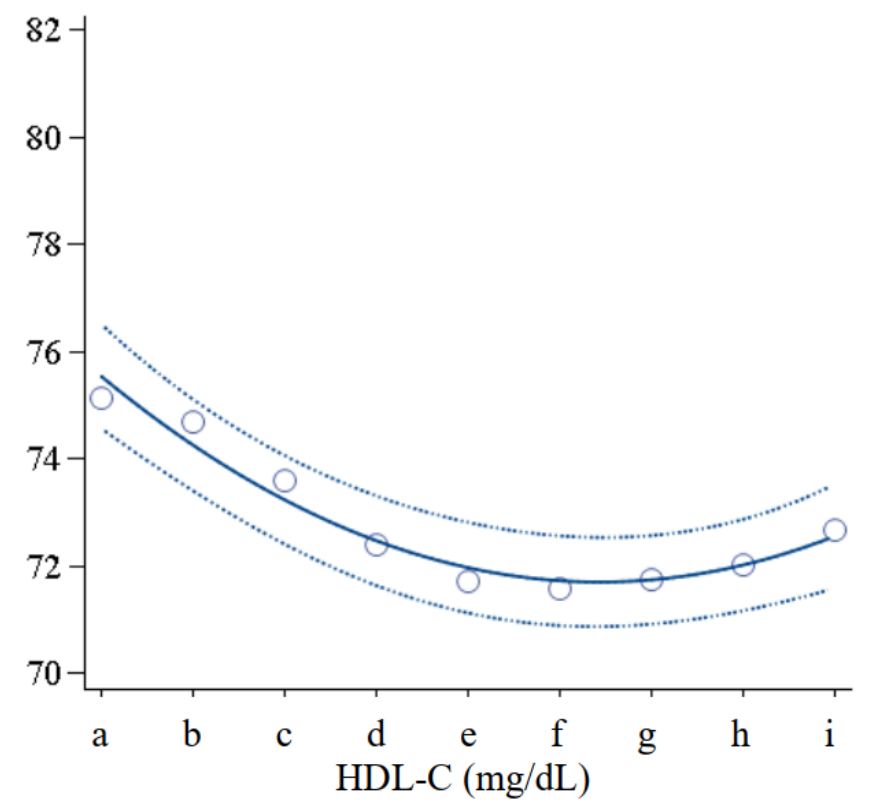

Figure 1. Cont. 

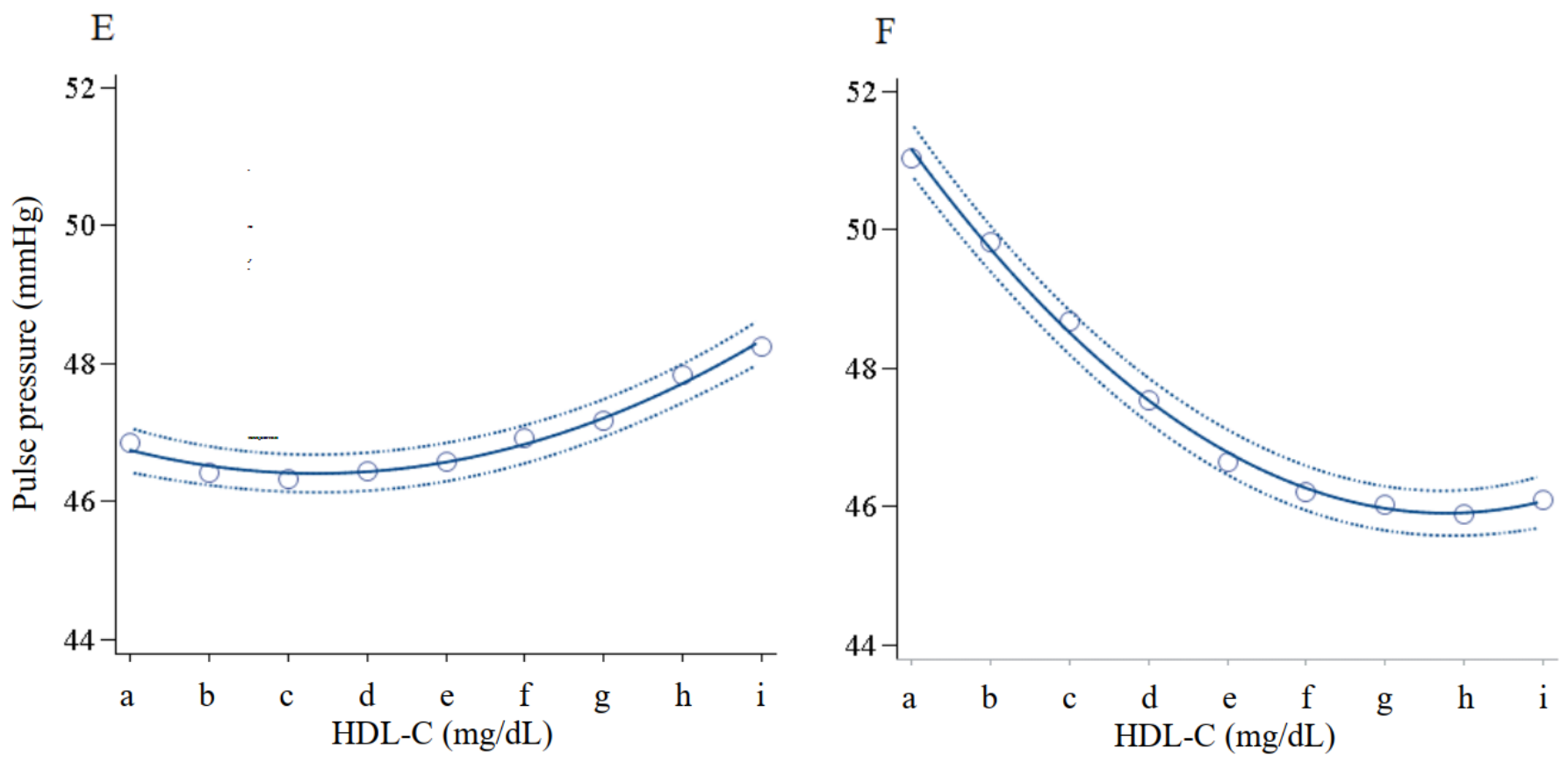

Figure 1. Blood pressure in men and women according to nine HDL-C concentration categories. With HDL-C concentrations of 20-39, 40-49, 50-59, 60-69, 70-79, 80-89, 90-99, 100-109, 110-119, and $\geq 120 \mathrm{mg} / \mathrm{dL}, \mathrm{n}=57,052,193,722,235,749,171,612$, $95,359,45,195,19,204,7624$, and 5152 for men and 6800, 44,379, 112,421, 160,350, 148,963, 99,424, 52,858, 22,886, and 14,402 for women, respectively. Open circle expresses mean of blood pressure in each HDL-C concentration category. Solid line and dashed line express quadratic regression curve and 95\%CIs. a, 20-39; b, 40-49; c, 50-59; d, 60-69; e, 70-79; f, 80-89; g, 90-99; h, 100-109; i, $\geq 110$ mg/dL. (A): Systolic blood pressure in men; (B): Systolic blood pressure in women; (C): Diastolic blood pressure in men; (D): Diastolic blood pressure in women; (E): Pulse pressure in men; (F): Pulse pressure in women.

Table 2. Prevalence of HBP according to nine HDL-C concentration categories.

\begin{tabular}{|c|c|c|c|c|c|c|c|c|c|}
\hline $\begin{array}{c}\text { HDL-C Category } \\
(\mathrm{mg} / \mathrm{dL})\end{array}$ & $20-39$ & $40-49$ & $50-59$ & $60-69$ & $70-79$ & $80-89$ & 90-99 & 100-109 & $\geq \mathbf{1 1 0}$ \\
\hline \multicolumn{10}{|l|}{$\begin{array}{l}\text { Whole subjects } \\
(\mathrm{n}=1,493,152)\end{array}$} \\
\hline $\begin{array}{c}\text { Case of HBP, } \\
\mathrm{n}(\% \text { in each group }) \\
\text { Men } \\
(\mathrm{n}=830,669)\end{array}$ & $\begin{array}{l}26,275 \\
(41.2)\end{array}$ & $\begin{array}{l}91,895 \\
(38.6)\end{array}$ & $\begin{array}{c}122,287 \\
(35.1)\end{array}$ & $\begin{array}{c}101,501 \\
(30.6)\end{array}$ & $\begin{array}{c}65,474 \\
(26.8)\end{array}$ & $\begin{array}{c}35,924 \\
(24.8)\end{array}$ & $\begin{array}{l}17,111 \\
(23.7)\end{array}$ & $\begin{array}{c}7461 \\
(24.5)\end{array}$ & $\begin{array}{c}5190 \\
(26.5)\end{array}$ \\
\hline $\begin{array}{c}\text { Case of HBP, } \\
\mathrm{n}(\% \text { in each group }) \\
\text { Women } \\
(\mathrm{n}=662,483)\end{array}$ & $\begin{array}{c}23,324 \\
(40.9)\end{array}$ & $\begin{array}{c}74,652 \\
(38.5)\end{array}$ & $\begin{array}{l}85,647 \\
(36.3)\end{array}$ & $\begin{array}{l}59,333 \\
(34.6)\end{array}$ & $\begin{array}{c}32,232 \\
(33.8)\end{array}$ & $\begin{array}{l}15,473 \\
(34.2)\end{array}$ & $\begin{array}{c}6680 \\
(34.8)\end{array}$ & $\begin{array}{l}2896 \\
(38.0)\end{array}$ & $\begin{array}{c}2104 \\
(40.8)\end{array}$ \\
\hline $\begin{array}{c}\text { Case of HBP, } \\
\mathrm{n}(\% \text { in each group) }\end{array}$ & $\begin{array}{c}2951 \\
(43.4)\end{array}$ & $\begin{array}{l}17,243 \\
(38.9)\end{array}$ & $\begin{array}{c}36,640 \\
(32.6)\end{array}$ & $\begin{array}{l}42,168 \\
(26.3)\end{array}$ & $\begin{array}{c}33,242 \\
(22.3)\end{array}$ & $\begin{array}{l}20,451 \\
(20.6)\end{array}$ & $\begin{array}{l}10,431 \\
(19.7)\end{array}$ & $\begin{array}{l}4565 \\
(20.0)\end{array}$ & $\begin{array}{l}3086 \\
(21.4)\end{array}$ \\
\hline
\end{tabular}

HBP was defined as blood pressure of $\geq 140 / 90 \mathrm{mmHg}$ and/or pharmacotherapy for hypertension.

\subsection{Subgroup Analysis}

In the subgroup of nondrinkers ( $n=595,268)$, HBP was observed in $29.6 \%$ of the whole, $31.5 \%$ of men, and $28.4 \%$ of women, respectively. As shown in the Table 3 , the prevalences of HBP were decreased across the increasing HDL-C in the whole subjects and women ( $p<0.0001$, Cochran-Armitage tests), whereas left-to-right inverted J-shaped relationship with a bottom of HDL-C of 90-99 $\mathrm{mg} / \mathrm{dL}$ was observed in men. 

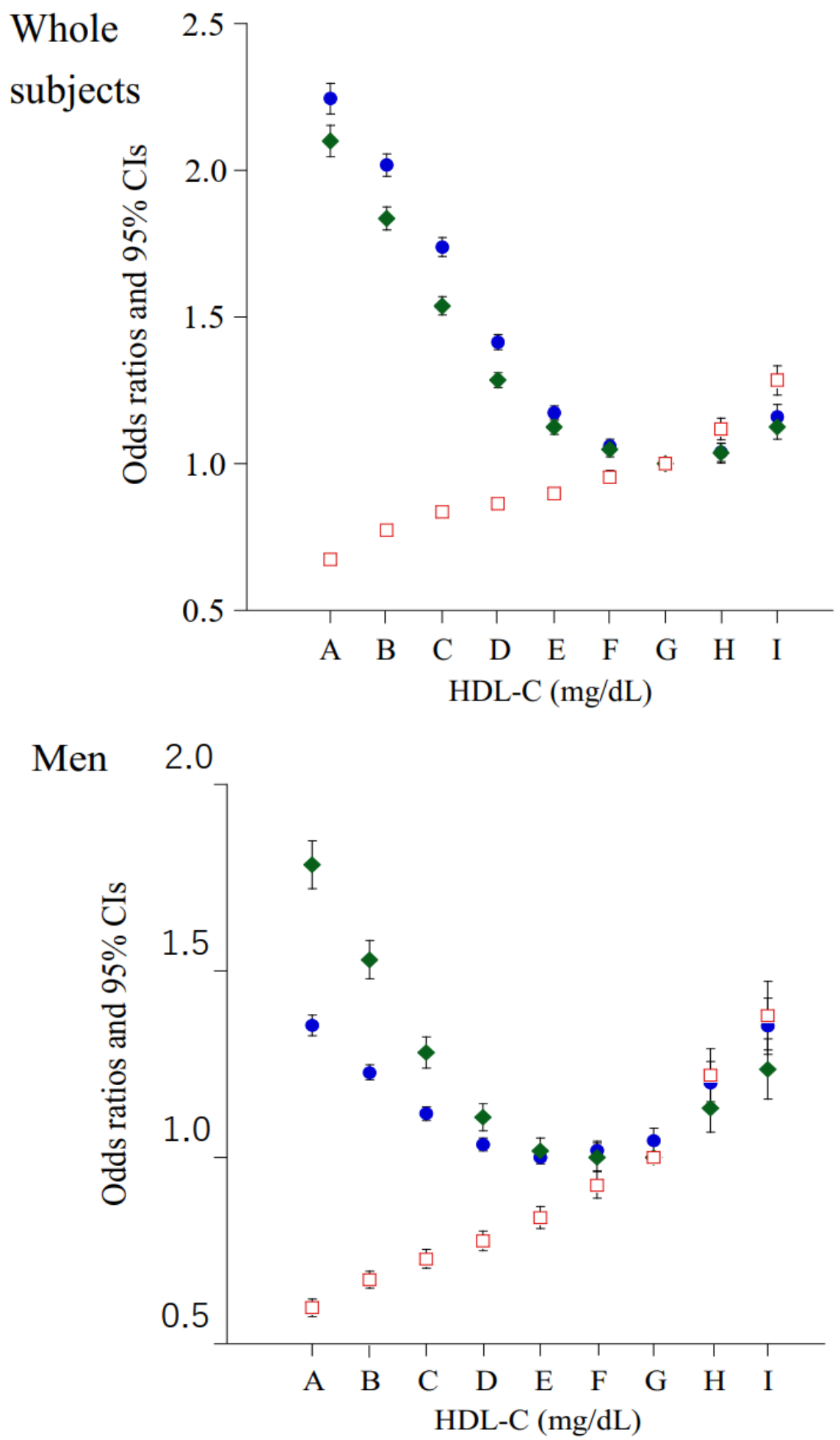

Figure 2. Cont. 


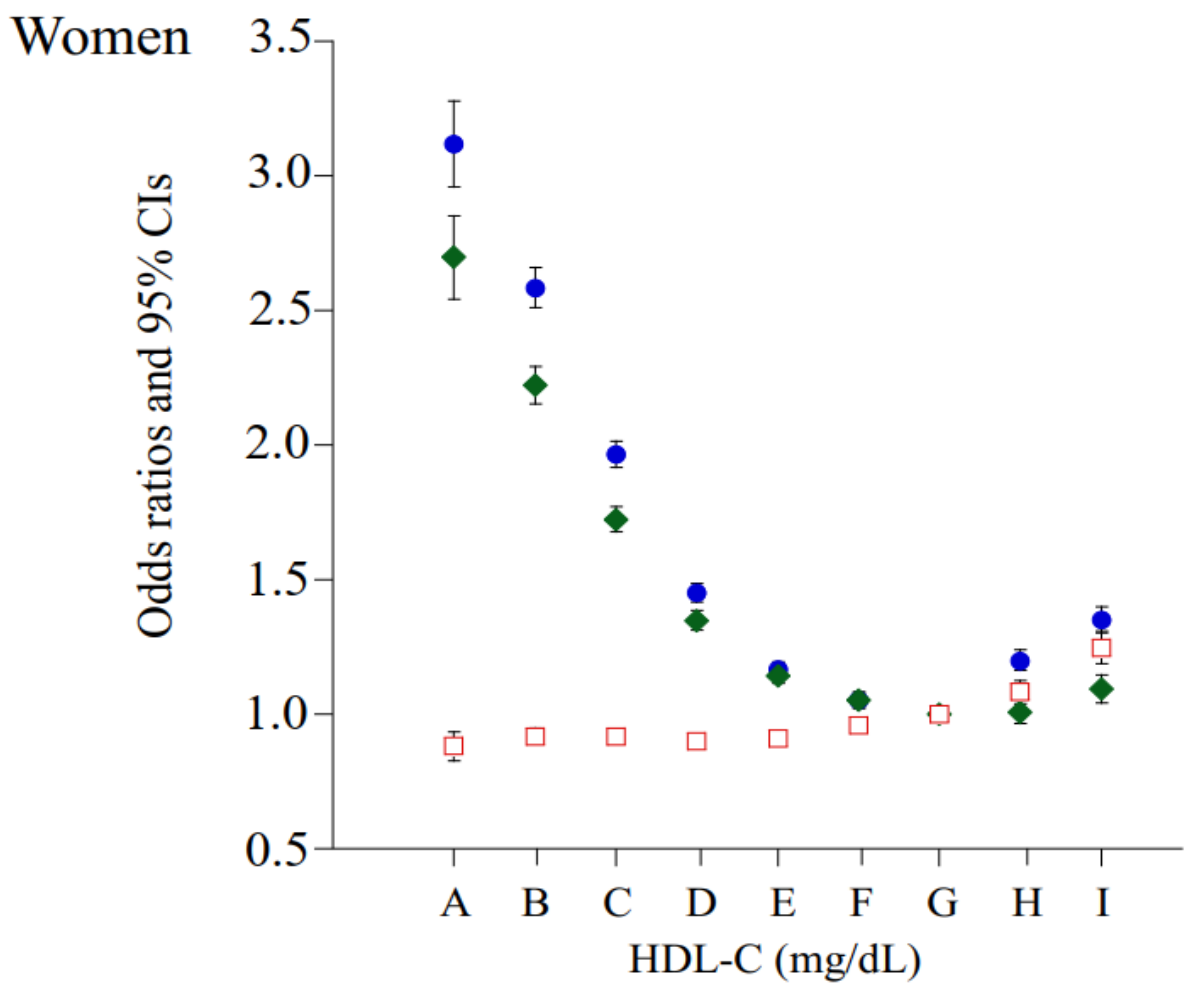

Figure 2. Odds ratios of nine HDL-C concentration categories for HBP. Closed blue circle: unadjusted. Closed green diamond: adjusted for age, sex (whole subjects), smoking, pharmacotherapy (for diabetes mellitus or dyslipidemia), habitual exercise, and daily alcohol consumption. Open red square: plus adjusted for body mass index and serum concentration of triglyceride A, 20-39; B, 40-49; C, 50-59; D, 60-69; E, 70-79; F, 80-89; G, 90-99; H, 100-109; I, 110 mg/dL.

Table 3. Prevalence of HBP according to nine HDL-C concentration categories in subjects who hardly consumed alcohol.

\begin{tabular}{|c|c|c|c|c|c|c|c|c|c|}
\hline $\begin{array}{c}\text { HDL-C Category } \\
(\mathrm{mg} / \mathrm{dL})\end{array}$ & $30-39$ & $40-49$ & $50-59$ & $60-69$ & $70-79$ & $80-89$ & 90-99 & 100-109 & $\geq \mathbf{1 1 0}$ \\
\hline $\begin{array}{c}\text { Whole subjects, } \mathrm{n} \\
\quad(\% \text { in total } \\
\mathrm{n}=595,268)\end{array}$ & $\begin{array}{c}30,758 \\
(5.2)\end{array}$ & $\begin{array}{c}100,349 \\
(16.9)\end{array}$ & $\begin{array}{c}137,781 \\
(23.1)\end{array}$ & $\begin{array}{c}131,843 \\
(22.1)\end{array}$ & $\begin{array}{l}96,651 \\
(16.2)\end{array}$ & $\begin{array}{c}55,464 \\
(9.3)\end{array}$ & $\begin{array}{c}26,373 \\
(4.4)\end{array}$ & $\begin{array}{c}10,397 \\
(1.7)\end{array}$ & $\begin{array}{l}5,652 \\
(0.9)\end{array}$ \\
\hline $\begin{array}{c}\text { Case of HBP, } \\
\text { n (\% in each group) }\end{array}$ & $\begin{array}{l}12,465 \\
(40.5)\end{array}$ & $\begin{array}{l}37,204 \\
(37.1)\end{array}$ & $\begin{array}{l}45,813 \\
(33.3)\end{array}$ & $\begin{array}{l}36,585 \\
(27.8)\end{array}$ & $\begin{array}{l}23,333 \\
(24.1)\end{array}$ & $\begin{array}{l}12,139 \\
(21.9)\end{array}$ & $\begin{array}{l}5,379 \\
(20.4)\end{array}$ & $\begin{array}{l}2,078 \\
(20.0)\end{array}$ & $\begin{array}{l}1,108 \\
(19.6)\end{array}$ \\
\hline $\begin{array}{c}\text { Men, } \mathrm{n} \\
(\% \text { in total } \\
\mathrm{n}=227,709)\end{array}$ & $\begin{array}{c}25,865 \\
(11.4)\end{array}$ & $\begin{array}{c}70,200 \\
(30.8)\end{array}$ & $\begin{array}{l}66,599 \\
(29.2)\end{array}$ & $\begin{array}{l}38,101 \\
(16.7)\end{array}$ & $\begin{array}{c}16,939 \\
(7.4)\end{array}$ & $\begin{array}{l}6,499 \\
(2.9)\end{array}$ & $\begin{array}{c}2,345 \\
(1.0)\end{array}$ & $\begin{array}{l}755 \\
(0.3)\end{array}$ & $\begin{array}{l}406 \\
(0.2)\end{array}$ \\
\hline $\begin{array}{c}\text { Case of HBP, } \\
\text { n (\% in each group) }\end{array}$ & $\begin{array}{l}10,235 \\
(39.6)\end{array}$ & $\begin{array}{l}24,756 \\
(35.3)\end{array}$ & $\begin{array}{l}20,628 \\
(31.0)\end{array}$ & $\begin{array}{l}9,887 \\
(26.0)\end{array}$ & $\begin{array}{l}4,053 \\
(23.9)\end{array}$ & $\begin{array}{l}1,410 \\
(21.7)\end{array}$ & $\begin{array}{c}493 \\
(21.0)\end{array}$ & $\begin{array}{c}174 \\
(23.1)\end{array}$ & $\begin{array}{c}99 \\
(24.4)\end{array}$ \\
\hline $\begin{array}{c}\text { Women, } \mathrm{n} \\
(\% \text { in total } \\
\mathrm{n}=367,559)\end{array}$ & $\begin{array}{l}4,893 \\
(1.3)\end{array}$ & $\begin{array}{c}30,149 \\
(8.2)\end{array}$ & $\begin{array}{c}71,182 \\
(19.4)\end{array}$ & $\begin{array}{l}93,742 \\
(25.5)\end{array}$ & $\begin{array}{c}79,712 \\
(21.7)\end{array}$ & $\begin{array}{l}48,965 \\
(13.3)\end{array}$ & $\begin{array}{c}24,028 \\
(6.5)\end{array}$ & $\begin{array}{l}9,642 \\
(2.6)\end{array}$ & $\begin{array}{l}5,246 \\
(1.4)\end{array}$ \\
\hline $\begin{array}{c}\text { Case of HBP, } \\
\mathrm{n}(\% \text { in each group })\end{array}$ & $\begin{array}{l}2,230 \\
(45.6)\end{array}$ & $\begin{array}{l}12,448 \\
(41.3)\end{array}$ & $\begin{array}{l}25,185 \\
(35.4)\end{array}$ & $\begin{array}{l}26,698 \\
(28.5)\end{array}$ & $\begin{array}{l}19,280 \\
(24.2)\end{array}$ & $\begin{array}{l}10,729 \\
(21.9)\end{array}$ & $\begin{array}{l}4,886 \\
(20.3)\end{array}$ & $\begin{array}{l}1,904 \\
(19.8)\end{array}$ & $\begin{array}{l}1,009 \\
(19.2)\end{array}$ \\
\hline
\end{tabular}

HBP was defined as blood pressure of $\geq 140 / 90 \mathrm{mmHg}$ and/or pharmacotherapy for hypertension.

Likewise, a crude logistic regression analysis showed inverse linear associations between HDL-C categories and HBP in the whole subjects and women, whereas left-toright inverted J-shaped relationship were observed in men (Figure 3). These trends were not altered after adjustment for smoking; habitual exercise; and pharmacotherapy for dyslipidemia and diabetes. However, after further adjustment for BMI and serum TG, the 
positive associations between low and normal HDL-C categories ( $\leq 90 \mathrm{mg} / \mathrm{dL}$ in men) and $\mathrm{HBP}$ were attenuated but remain, and the relationships transformed into blunt U-shaped relationships with a bottom of HDL-C of $60-69 \mathrm{mg} / \mathrm{dL}$ in both men and women.

\subsection{Discussion}

Using a large healthcare dataset of 1.5 million general people, our study investigated complicated associations between serum HDL-C concentration and blood pressure, both of which are pivotal to the incidence of CVD and mortality and are simultaneously influenced by genetic background, comorbidities, and lifestyle factors, such as alcohol consumption, exercise, smoking, and body weight.

At first, our study demonstrated crude U-shaped relationship between serum HDL-C concentration and blood pressures. Similar relationships were also observed between serum HDL-C concentration and pulse pressure, which is a marker of atherosclerosis and a hyperdynamic circulation $[35,36]$.

Overall, confounders adjusted ORs showed left-to-right inverted J-shaped relationship with a bottom of HDL-C of 90-99 mg/dL in men and women, which suggests that both low and extremely high HDL-C $(\geq 100 \mathrm{mg} / \mathrm{dL})$ are likely to be associated with HBP.

Positive association between extremely high HDL-C and HBP remained even after adjusting for BMI and serum TG in nondrinkers. Adjustment for BMI and serum TG may disclose different pathophysiology by eliminating the effect of excess body weight. Because BMI and serum TG were normal or low on average in the very and extremely high HDL-C groups ( $\geq 100 \mathrm{mg} / \mathrm{dL}$ ), adjustment for BMI and TG did not change the association between high HDL-C concentration and HBP.

However, the positive association was attenuated even in men when subjects were restricted to the subgroup of nondrinkers, suggesting that this association may be largely dependent on frequent alcohol consumption, which was shown to raise serum HDL-C via inhibition of CETP activity and activation of lipoprotein lipase [37,38].

\section{Whole subjects}

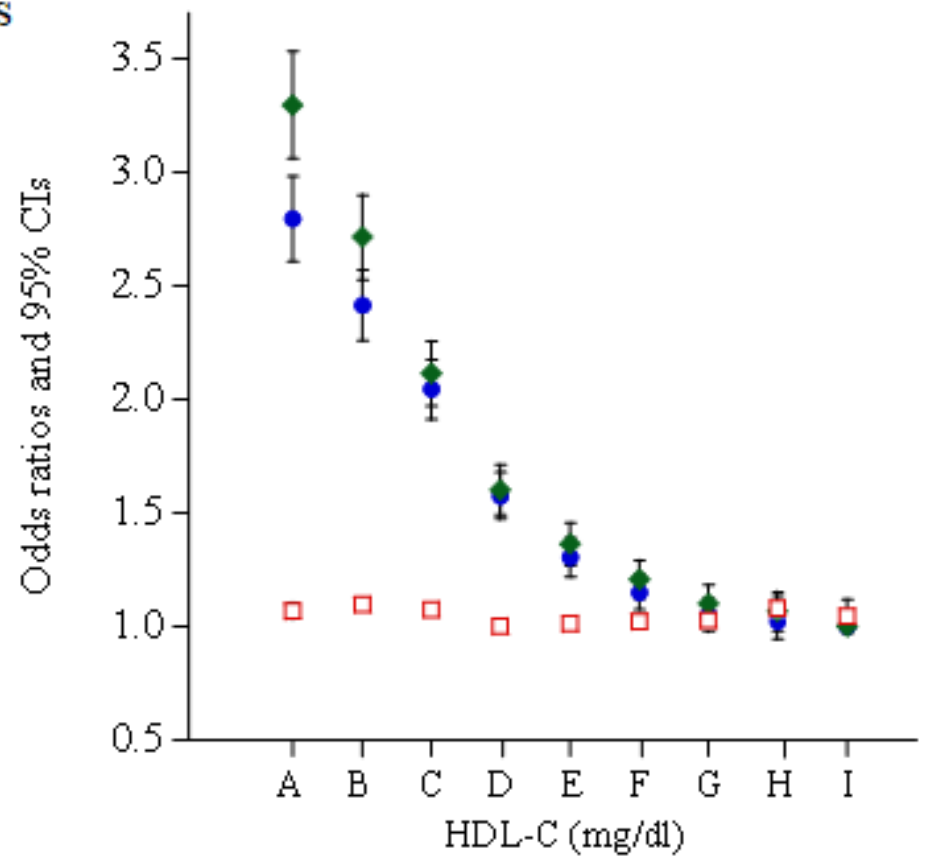

Figure 3. Cont. 
Men

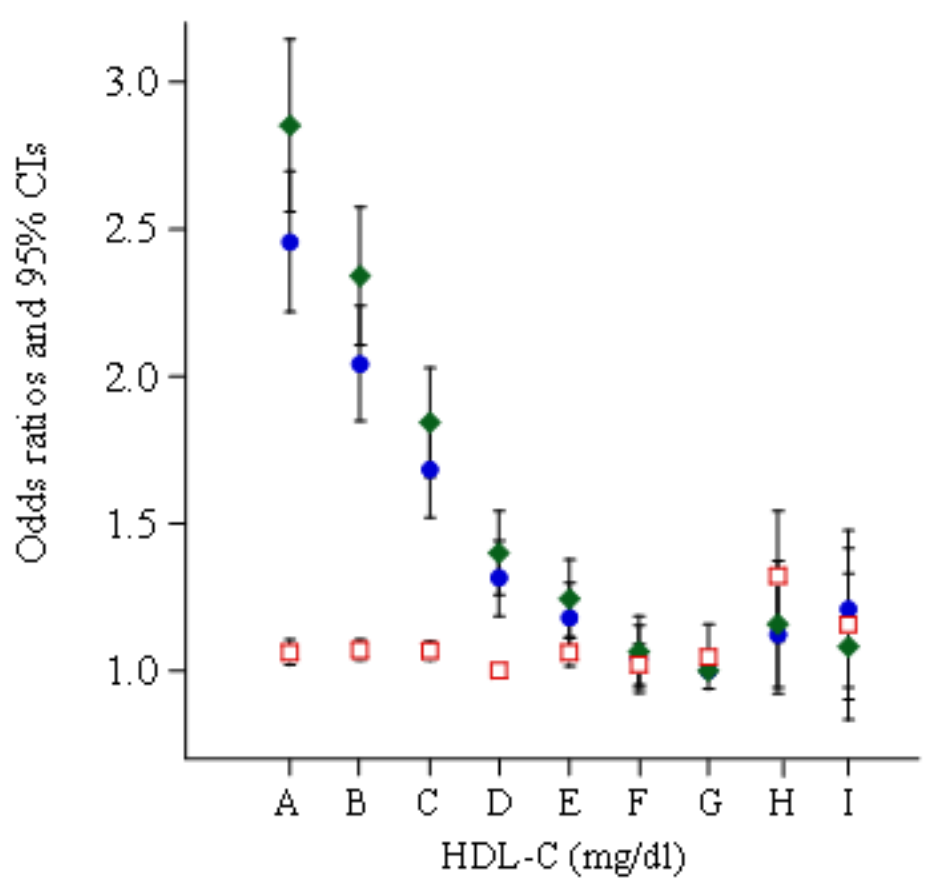

Women

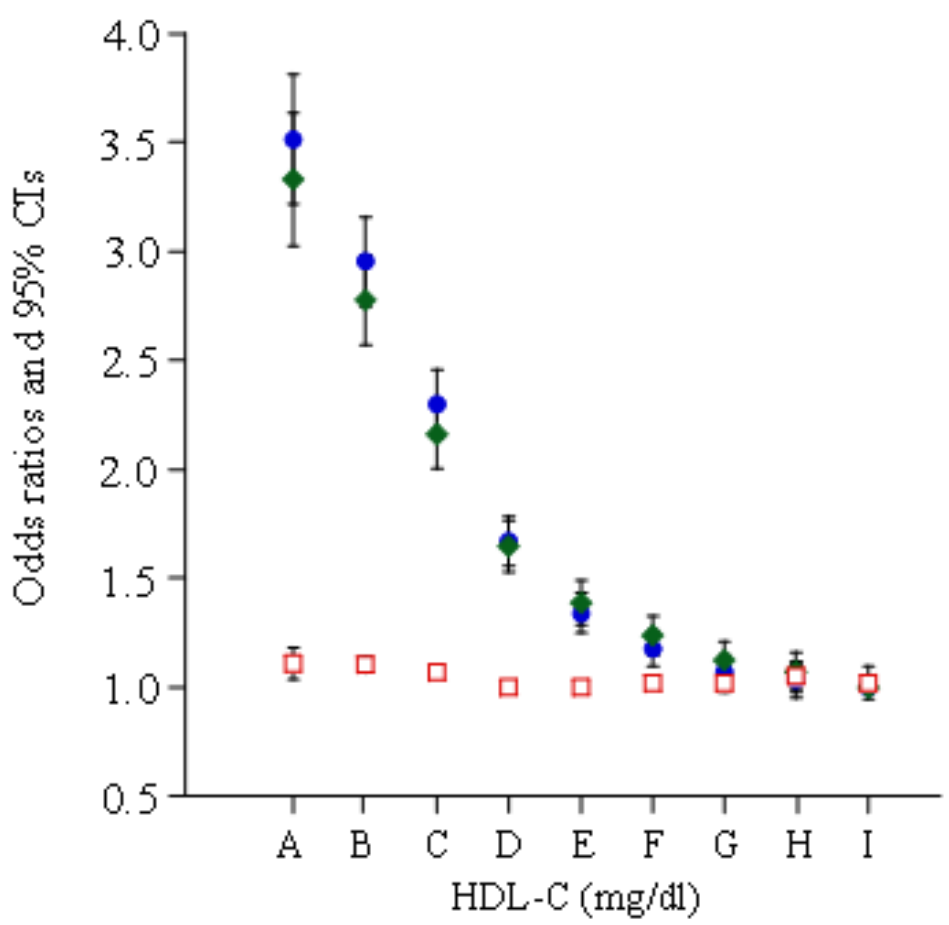

Figure 3. Odds ratios of nine HDL-C concentration categories for HBP in subjects who hardly consumed alcohol. Closed blue circle: unadjusted. Closed green diamond: adjusted for age, sex (whole subjects), smoking, pharmacotherapy (for diabetes mellitus or dyslipidemia), habitual exercise, and daily alcohol consumption. Open red square: plus adjusted for body mass index and serum concentration of triglyceride A, 20-39; B, 40-49; C, 50-59; D, 60-69; E, 70-79; F, 80-89; G, 90-99; H, 100-109; I, $\geq 110 \mathrm{mg} / \mathrm{dL}$. 
On the other hand, positive associations between low HDL-C categories and HBP were disappeared and inverted after adjustment for BMI and serum TG. Because a high BMI and serum TG concentration usually reflect obesity, positive associations between low HDL-C categories and HBP might be dependent on an excess body fat mass.

Intriguingly, such inversions were not observed in the subgroup of nondrinkers and when HBP was replaced with pharmacotherapy for hypertension. The former may be attributable to relatively lower BMI and serum TG in the nondrinkers compared with drinkers, which were confirmed in this study (albeit data is not shown), whereas the cause for the latter is unknown.

In this study, blood pressure was measured with an automated sphygmomanometer at checkup center but not at home. Therefore, the HBP determined in this study is likely to include the effect of white-coat hypertension $[39,40]$. However, as shown in Figure S1, similar U or J-shaped association of low and high HDL-C were observed with the pharmacotherapy for hypertension, which reflects already diagnosed hypertension in a clinical practice and is unrelated with the blood pressures measured at a checkup. In addition, current blood pressures are not conventional blood pressures measured manually in the presence of attending physician or nurse in a clinical practice. Furthermore, in recent years, it was shown that automatically measured office blood pressures are comparable to home blood pressures [41-43]. These may support current main results of relationship between HDL-C and HBP.

The underlying mechanism behind these fundamental positive linear associations is unknown. Unmeasured factors, such as heart rate; endocrine disorders accompanied by elevated catecholamines, cortisol, aldosterone, thyroid hormones, and sodium consumption, might contribute to these associations. In addition, it is unknown whether the nature of HBP in individuals with high HDL-C, if any, differs from that in individuals with low HDL-C, which needs further study.

In recent years, several studies showed that extremely high serum HDL-C may not be protective against CVD development [8-14]. Some of these studies presented U-shaped or positive linear relationships between HDL-C concentration categories and blood pressure $[9,11,13]$, although the authors did not particularly argue them in their articles. Furthermore, none of these studies investigated pulse pressure in terms of HDL-C concentration categories.

In addition, clinical trials evaluating the effects of CETP inhibitors, which do not show a protective effect against CVD events, demonstrated a slightly increase in systolic blood pressure of 1.2-5.4 mmHg after intervention, concomitant with a substantial increase in HDL-C concentration $[15,16]$.

Likewise, in our study, the difference in systolic blood pressure between the reference HDL-C concentration group and the extremely high HDL-C concentration group was small (6 mmHg at most in males) (Figure 1), which is coincidently equivalent to the increase in blood pressure caused by CETP inhibitors, as outlined above. However, it is unknown whether there is a common mechanism underpinning the pathophysiology between a naturally high HDL-C concentration and HDL-C raised by pharmacotherapy. Further study will be needed to confirm whether this small increase in blood pressure has clinical significance in patients with atherosclerosis and CVD.

\subsection{Limitations}

This study has some limitations. Firstly, strictly speaking, HBP at checkup is unlikely to be hypertension, which warrants further study including home blood pressures. Secondly, the causality between HDL-C concentration and HBP could not be identified, since this study adopted a cross-sectional design, despite of the large database. Thirdly, because subjects in this study were general people who underwent a health checkup, most were healthy and free from CVD and hypertension. Therefore, the results may not be applicable to other populations or patients with CVD and hypertension. Forthly, secondary hypertension and dyslipidemia, and genetic familial hypercholesterolemia were not excluded in 
this study, if any. Finally, the contents of pharmacotherapy for hypertension, which can influence the metabolism of lipids $[44,45]$, the data of renal function and serum uric acid, which contribute to the development of hypertension [46-49], and the data of diet were also unavailable in this study. Further studies addressing these limitations are needed to warrant current results.

\section{Conclusions}

The association between HDL-C concentration and blood pressure is complicated and differs between people who consume alcohol and those who do not. In clinical practice, an apparent inverse association between HDL-C concentration (30-70 mg/dL, which is the frequently observed range) and HBP may be observed, although this association can depend on body fat mass. The robust association between an extremely high HDL-C concentration and HBP, particularly in men, and the fundamental positive linear association between HDL-C concentration and HBP may challenge the traditional concept of "the higher, the better" and the high HDL-C concentration caused by CETP inhibitors. Further studies, including long-term prospective studies and clinical trials, on pharmacotherapy intervention are needed to confirm our results.

Supplementary Materials: The following are available online at https://www.mdpi.com/article/10 $.3390 /$ jcm10215118/s1. Figure S1: Odds ratios of nine HDL-C concentration categories for pharmacotherapy for hypertension.

Author Contributions: K.N. and T.N. contributed to the overall study design. K.N., R.H., and K.T. contributed to the interpretation of the initial analysis and the discussion of the literature. K.N. conducted the data preparation and analysis. K.M. and R.H. prepared data and software. K.N. prepared the first draft of the manuscript, and both authors read and approved the manuscript. M.I., Conceptualization, Investigation and Writing - review \& editing. All authors have read and agreed to the published version of the manuscript.

Funding: This research received no external funding.

Institutional Review Board Statement: The study was conducted according to the guidelines of the Declaration of Helsinki, and approved by the Institutional Review Board of the Ethics Committee of Kanagawa University of Human Services (10-43) and the MHLW of Japan (No. 121).

Informed Consent Statement: Not required because of anonymous data from the MHLW of Japan, as part of its nationwide program involving the provision of medical data to third parties. Instead, we have opened the study protocol online (https:/ / www.kuhs.ac.jp/research/nationaldatabase/).

Acknowledgments: We thank Emily Woodhouse for editing a draft of this manuscript.

Conflicts of Interest: The authors declare no conflict of interest.

\section{Abbreviations}

BMI: body mass index; CETP, cholesteryl ester transfer protein; CVD, cardiovascular disease; HDL-C, High-density lipoprotein; MHLW, Ministry of Health, Labour, and Welfare; TG, triglyceride.

\section{References}

1. Martinez, L.; Jacquet, S.; Collet, X.; Perret, B.; Barbaras, R. New insight on the molecular mechanisms of high-density lipoprotein cellular interactions. Cell. Mol. Life Sci. 2004, 61, 2343-2360. [CrossRef]

2. Bermúdez, V.; Cano, R.; Cano, C.; Bermúdez, F.; Arraiz, N.; Acosta, L.; Finol, F.; Pabón, M.R.; Amell, A.; Reyna, N.; et al. Pharmacologic management of isolated low high-density lipoprotein syndrome. Am. J. Ther. 2008, 15, 377-388. [CrossRef]

3. Tomlinson, B. Raising high-density lipoprotein: For better or worse? Heart 2010, 96, 1339-1340. [CrossRef]

4. Feig, J.E.; Hewing, B.; Smith, J.D.; Hazen, S.L.; Fisher, E.A. High-density lipoprotein and atherosclerosis regression: Evidence from preclinical and clinical studies. Circ. Res. 2014, 114, 205-213. [CrossRef]

5. Toth, P.P.; Barylski, M.; Nikolic, D.; Rizzo, M.; Montalto, G.; Banach, M. Should low high-density lipoprotein cholesterol (HDL-C) be treated? Best Pract. Res. Clin. Endocrinol. Metab. 2014, 28, 353-368. [CrossRef] [PubMed] 
6. Landi, F.; Russo, A.; Pahor, M.; Capoluongo, E.; Liperoti, R.; Cesari, M.; Bernabei, R.; Onder, G. Serum high-density lipoprotein cho-lesterol levels and mortality in frail, community-living elderly. Gerontology 2008, 54, 71-78. [CrossRef] [PubMed]

7. Rahilly-Tierney, C.R.; Spiro, A., 3rd; Vokonas, P.; Gaziano, J.M. Relation between high-density lipoprotein cholesterol and survival to age 85 years in men (from the VA normative aging study). Am. J. Cardiol. 2011, 107, 1173-1177. [CrossRef]

8. Sun, Y.; Yang, Y.; Pei, W.; Wu, Y.; Zhao, J. Is Elevated High-density Lipoprotein Cholesterol Always Good for Coronary Heart Disease? Clin. Cardiol. 2007, 30, 576-580. [CrossRef] [PubMed]

9. Ko, D.T.; Alter, D.A.; Guo, H.; Koh, M.; Lau, G.; Austin, P.C.; Booth, G.L.; Hogg, W.; Jackevicius, C.A.; Lee, D.S.; et al. HighDensity Lipoprotein Cholesterol and Cause-Specific Mortality in Individuals Without Previous Cardiovascular Conditions: The CANHEART Study. J. Am. Coll Cardiol. 2016, 68, 2073-2083. [CrossRef] [PubMed]

10. Madsen, C.M.; Varbo, A.; Nordestgaard, B.G. Extreme high high-density lipoprotein cholesterol is paradoxically associated with high mortality in men and women: Two prospective cohort studies. Eur. Heart J. 2017, 38, 2478-2486. [CrossRef] [PubMed]

11. Hirata, A.; Sugiyama, D.; Watanabe, M.; Tamakoshi, A.; Iso, H.; Kotani, K.; Kiyama, M.; Yamada, M.; Ishikawa, S.; Murakami, Y.; et al. Association of extremely high levels of high-density lipoprotein cholesterol with cardiovascular mortality in a pooled analysis of 9 cohort studies including 43,407 individuals: The EPOCH-JAPAN study. J. Clin. Lipidol. 2018, 12, 674-684.e5. [CrossRef] [PubMed]

12. Li, X.; Guan, B.; Wang, Y.; Tse, G.; Zou, F.; Khalid, B.W.; Xia, Y.; Wu, S.; Sun, J. Association between high-density lipoprotein cholesterol and all-cause mortality in the general population of northern China. Sci. Rep. 2019, 9, 1-8. [CrossRef]

13. Huang, Y.-Q.; Liu, X.-C.; Lo, K.; Liu, L.; Yu, Y.-L.; Chen, C.-L.; Huang, J.-Y.; Feng, Y.-Q.; Zhang, B. The U Shaped Relationship Between High-Density Lipoprotein Cholesterol and All-Cause or Cause-Specific Mortality in Adult Population. Clin. Interv. Aging 2020, 15, 1883-1896. [CrossRef]

14. Chen, C.-L.; Liu, X.-C.; Liu, L.; Lo, K.; Yu, Y.-L.; Huang, J.-Y.; Huang, Y.-Q.; Chen, J.-Y. U-Shaped Association of High-Density Lipoprotein Cholesterol with All-Cause and Cardiovascular Mortality in Hypertensive Population. Risk Manag. Health Policy 2020, 13, 2013-2025. [CrossRef] [PubMed]

15. Barter, P.J.; Caulfield, M.; Eriksson, M.; Grundy, S.M.; Kastelein, J.J.P.; Komajda, M.; Lopez-Sendon, J.; Mosca, L.; Tardif, J.-C.; Waters, D.D.; et al. Effects of Torcetrapib in Patients at High Risk for Coronary Events. N. Engl. J. Med. 2007, 357, 2109-2122 [CrossRef] [PubMed]

16. Lincoff, A.M.; Nicholls, S.J.; Riesmeyer, J.S.; Barter, P.J.; Brewer, H.B.; Fox, K.A.A.; Gibson, C.M.; Granger, C.; Menon, V.; Montalescot, G.; et al. Evacetrapib and Cardiovascular Outcomes in High-Risk Vascular Disease. N. Engl. J. Med. 2017, 376, 1933-1942. [CrossRef] [PubMed]

17. Riaz, H.; Khan, S.U.; Rahman, H.; Shah, N.P.; Kaluski, E.; Lincoff, A.M.; Nissen, S. Effects of high-density lipoprotein targeting treatments on cardiovascular outcomes: A systematic review and meta-analysis. Eur. J. Prev. Cardiol. 2019, 26, 533-543. [CrossRef]

18. Whyte, M.B. Is high-density lipoprotein a modifiable treatment target or just a biomarker for cardiovascular disease? JRSM Cardiovasc. Dis. 2019, 8, 2048004019869736. [CrossRef] [PubMed]

19. Li, C.; Zhang, W.; Zhou, F.; Chen, C.; Zhou, L.; Li, Y.; Liu, L.; Pei, F.; Luo, H.; Hu, Z.; et al. Cholesteryl ester transfer protein in-hibitors in the treatment of dyslipidemia: A systematic review and meta-analysis. PLoS ONE 2013, 8, e77049.

20. Filippatos, T.D.; Klouras, E.; Barkas, F.; Elisaf, M. Cholesteryl ester transfer protein inhibitors: Challenges and perspectives. Expert Rev. Cardiovasc. Ther. 2016, 14, 953-962. [CrossRef]

21. Rios, F.; Lopes, R.; Neves, K.B.; Camargo, L.D.L.; Montezano, A.C.; Touyz, R.M. Off-Target Vascular Effects of Cholesteryl Ester Transfer Protein Inhibitors Involve Redox-Sensitive and Signal Transducer and Activator of Transcription 3-Dependent Pathways. J. Pharmacol. Exp. Ther. 2016, 357, 415-422. [CrossRef] [PubMed]

22. Yan, W.; Gu, D.; Yang, X.; Wu, J.; Kang, L.; Zhang, L. High-density lipoprotein cholesterol levels increase with age, body mass index, blood pressure and fasting blood glucose in a rural Uygur population in China. J. Hypertens. 2005, 23, 1985-1989. [CrossRef]

23. Oda, E.; Kawai, R. High-density lipoprotein cholesterol is positively associated with hypertension in apparently healthy Japanese men and women. Br. J. Biomed. Sci. 2011, 68, 29-33. [CrossRef]

24. Kawamoto, R.; Tabara, Y.; Kohara, K.; Miki, T.; Abe, M.; Kusunoki, T. Increased high-density lipoprotein cholesterol is associated with a high prevalence of pre-hypertension and hypertension in community-dwelling persons. Endocrine 2012, 42, 321-328. [CrossRef]

25. Nakajima, K.; Higuchi, R.; Mizusawa, K.; Nakamura, T. Association between extremely high high-density lipoprotein-cholesterol and hypertensive retinopathy: Results of a cross-sectional study from Kanagawa Investigation of Total Checkup Data from the National Database-6 (KITCHEN-6). BMJ Open 2021, 11, e043677. [CrossRef]

26. Nakajima, K.; Iwane, T.; Higuchi, R.; Shibata, M.; Takada, K.; Uda, J.; Anan, M.; Sugiyama, M.; Nakamura, T. Kanagawa Investigation of the Total Check-up Data from the National database (KITCHEN): Protocol for data-driven population-based repeated cross-sectional and 6-year cohort studies. BMJ Open 2019, 9, e023323. [CrossRef]

27. Chen, Y.; Zhang, D.-Y.; Li, Y.; Wang, J.-G. The Role of Out-of-Clinic Blood Pressure Measurements in Preventing Hypertension. Curr. Hypertens. Rep. 2018, 20, 85. [CrossRef]

28. Hoshide, S.; Kario, K.; Tomitani, N.; Kabutoya, T.; Chia, Y.; Park, S.; Shin, J.; Turana, Y.; Tay, J.C.; Buranakitjaroen, P.; et al. Highlights of the 2019 Japanese Society of Hypertension Guidelines and perspectives on the management of Asian hypertensive patients. J. Clin. Hypertens. 2020, 22, 369-377. [CrossRef] [PubMed] 
29. Tsushita, K.; SHosler, A.; Miura, K.; Ito, Y.; Fukuda, T.; Kitamura, A.; Tatara, K. Rationale and Descriptive Analysis of Specific Health Guidance: The Nationwide Lifestyle Intervention Program Targeting Metabolic Syndrome in Japan. J. Atheroscler. Thromb. 2018, 25, 308-322. [CrossRef] [PubMed]

30. Ministry of Health, Labour and Welfare. Health Examination and Guidance Program for Japanese Adults. 2008. Available online: https://www.mhlw.go.jp/bunya/shakaihosho/iryouseido01/info02a.html (accessed on 24 March 2020).

31. Available online: http://www.jacd.info/method/ketsuatsusokutei.htm (accessed on 19 September 2021).

32. Available online: https://www.mhlw.go.jp/content/10900000/000496780.pdf (accessed on 19 September 2021).

33. Flegal, K.M.; Cauley, J. Alcohol Consumption and Cardiovascular Risk Factors. Recent Dev. Alcohol. 1985, 3, 165-180. [CrossRef]

34. Criqui, M.H. Do Known Cardiovascular Risk Factors Mediate the Effect of Alcohol on Cardiovascular Disease? Novartis Found Symp. 2007, 216, 159-172. [CrossRef]

35. Kodama, S.; Horikawa, C.; Fujihara, K.; Yoshizawa, S.; Yachi, Y.; Tanaka, S.; Ohara, N.; Matsunaga, S.; Yamada, T.; Hanyu, O.; et al. Meta-Analysis of the Quantitative Relation Between Pulse Pressure and Mean Arterial Pressure and Cardiovascular Risk in Patients With Diabetes Mellitus. Am. J. Cardiol. 2014, 113, 1058-1065. [CrossRef] [PubMed]

36. Tang, K.S.; Medeiros, E.D.; Shah, A.D. Wide pulse pressure: A clinical review. J. Clin. Hypertens. 2020, 22, 1960-1967. [CrossRef] [PubMed]

37. Nishiwaki, M.; Ishikawa, T.; Ito, T.; Shige, H.; Tomiyasu, K.; Nakajima, K.; Kondo, K.; Hashimoto, H.; Saitoh, K.; Manabe, M.; et al. Effects of alcohol on lipoprotein lipase, hepatic lipase, cholesteryl ester transfer protein, and lecithin:cholesterol acyltransferase in high-density lipoprotein cholesterol elevation. Atherosclerosis 1994, 111, 99-109. [CrossRef]

38. Hannuksela, M.L.; Rantala, M.; Kesaniemi, Y.A.; Savolainen, M.J. Ethanol-Induced Redistribution of Cholesteryl Ester Transfer Protein (CETP) Between Lipoproteins. Arter. Thromb. Vasc. Biol. 1996, 16, 213-221. [CrossRef]

39. Roerecke, M.; Kaczorowski, J.; Myers, M.G. Comparing Automated Office Blood Pressure Readings with Other Methods of Blood Pressure Measurement for Identifying Patients With Possible Hypertension: A Systematic Review and Meta-analysis. JAMA Intern Med. 2019, 179, 351-362. [CrossRef] [PubMed]

40. Bo, Y.; Kwok, K.O.; Chu, K.K.; Leung, E.Y.; Yu, C.P.; Wong, S.Y.; Lee, E.K. Comparison Between Automated Office Blood Pressure Meas-urements and Manual Office Blood Pressure Measurements-Implications in Individual Patients: A Systematic Review and Meta-analysis. Curr. Hypertens. Rep. 2021, 23, 4. [CrossRef]

41. Jardim, T.V.; Gaziano, T.A.; Nascente, F.M.; Carneiro, C.D.S.; Morais, P.; Roriz, V.; Mendonça, K.L.; Póvoa, T.I.R.; Barroso, W.K.S.; Sousa, A.L.L.; et al. Office blood pressure measurements with oscillometric devices in adolescents: A comparison with home blood pressure. Blood Press. 2017, 26, 272-278. [CrossRef] [PubMed]

42. Myers, M.G.; Kaczorowski, J. Are Automated Office Blood Pressure Readings More Variable Than Home Readings? Hypertension 2020, 75, 1179-1183. [CrossRef] [PubMed]

43. Kadowaki, S.; Kadowaki, T.; Hozawa, A.; Fujiyoshi, A.; Hisamatsu, T.; Satoh, A.; Arima, H.; Tanaka, S.; Torii, S.; Kondo, K.; et al. Differences between home blood pressure and strictly measured office blood pressure and their determinants in Japanese men. Hypertens. Res. 2021, 44, 80-87. [CrossRef]

44. DeRosa, G.; Maffioli, P. Nifedipine and telmisartan for the treatment of hypertension: The TALENT study. Expert Rev. Cardiovasc. Ther. 2011, 9, 1499-1503. [CrossRef] [PubMed]

45. Grosskopf, I.; Shaish, A.; Charach, G.; Harats, D.; Kamari, Y. Nifedipine Treatment for Hypertension is Associated with Enhanced Lipolytic Activity and Accelerated Clearance of Postprandial Lipemia. Horm. Metab. Res. 2016, 48, 257-262. [CrossRef] [PubMed]

46. Thomas, G. Hypertension Management in Chronic Kidney Disease and Diabetes: Lessons from the Systolic Blood Pressure Intervention Trial. Cardiol. Clin. 2019, 37, 307-317. [CrossRef]

47. Teo, B.W.; Chan, G.C.; Leo, C.C.H.; Tay, J.C.; Chia, Y.; Siddique, S.; Turana, Y.; Chen, C.; Cheng, H.; Hoshide, S.; et al. Hypertension and chronic kidney disease in Asian populations. J. Clin. Hypertens. 2021, 23, 475-480. [CrossRef] [PubMed]

48. Feig, D. Serum uric acid and the risk of hypertension and chronic kidney disease. Curr. Opin. Rheumatol. 2014, 26, 176-185. [CrossRef]

49. Bjornstad, P.; Laffel, L.; Lynch, J.; El Ghormli, L.; Weinstock, R.S.; Tollefsen, S.E.; Nadeau, K.J.; TODAY Study Group. Elevated Serum Uric Acid Is Associated with Greater Risk for Hypertension and Diabetic Kidney Diseases in Obese Adolescents with Type 2 Dia-betes: An Observational Analysis from the Treatment Options for Type 2 Diabetes in Adolescents and Youth (TODAY) Study. Diabetes Care 2019, 42, 1120-1128. [PubMed] 